\title{
PROFESSOR DR. EGÍDIO J. ROMANELI FALA SOBRE A PSICOLOGIA E DÁ UMA AULA DE VIDA
}

\author{
Professor Dr. Egídio J. Romaneli Talks About \\ Psychology and Gives a Lesson of Life
}

\author{
Juliana Zamulak ${ }^{1}$ \\ Luciene Rocha Vasconcelos da Silva ${ }^{1}$ \\ Michel Alexandre Fillus ${ }^{1}$ \\ Nereu Souza Novais Filho ${ }^{1}$ \\ RenateB. Vicente ${ }^{2}$
}

Graduado em Letras Clássicas e Filosofia pela Faculdade de Filosofia, Ciências e Letras Nossa Senhora Medianeira, com Doutorado em Psicofisiologia, na França, pela Université de Toulouse e Pósdoutorado na área de Neuropsicologia, no Canadá, pela Université de Montreal. Atualmente, é professor Titular da Pontifícia Universidade Católica do Paraná, Professor Adjunto IV, aposentado, da Universidade Federal do Paraná.

Pergunta: Como foi a sua trajetória profissional?

Resposta: Quando concluí o curso na França, soube que estava para ser aberto o $1^{\circ}$ curso de Psicologia do Paraná. Então vim para Curitiba e em 1969 organizei o curso da PUC, onde acompanhei a 1 $^{\mathrm{a}}$ turma até o final, elaborando toda a documentação até o reconhecimento do curso. Fundei o Laboratório de Psicologia experimental da PUC, a seguir o da Federal do Paraná e também da Universidade Tuiti.

Na PUC eu era coordenador e tinha uma carga horária de 30 horas-aula. Não havia psicólogos na cidade; vieram alguns gaúchos que deram o respaldo inicial, mas não podiam assumir todas as disciplinas. Eu me vali de praticamente todos os médicos psiquiatras disponíveis na cidade. Por falta de tempo, depois que o curso de Psicologia da PUC já estava reconhecido, pedi demissão e fiquei somente com o Curso de Medicina, onde até hoje leciono Psicologia Médica.

$\mathrm{Na}$ Universidade Federal do Paraná comecei me encaminhando para a minha área, lecionando e pesquisando Neuropsicologia. Fui o pioneiro nesta área. Hoje já temos uma meia dúzia de doutores e mais ou menos 15 a 20 mestres. É com estes profissionais que provavelmente nos próximos 4 ou 5 anos teremos um mestrado em Neuropsicologia em Curitiba. Este é o meu sonho.

Graduandos do curso de Psicologia da PUCPR Curitiba-PR. e-mail: juliana.zamulak@pucpr.br; lucienerocha@hotmail.com; michelfillus@hotmail.com; nereu.souza@pucpr.br

2 Professora do Programa de Aprendizagem Laboratório e Desenvolvimento Profissional, do curso de Psicologia da PUCPR, CuritibaPR. Esta entrevista teve como finalidade abordar o papel do psicólogo na sua prática. Curitiba-PR. e-mail: renate.b@pucpr.br 
Na Universidade Federal do Paraná realizamos uma grande pesquisa com os testes neuropsicológicos do LURIA. Ultimamente fizemos uma pesquisa envolvendo mais de mil crianças e adolescentes para uma revalidação da bateria dos testes. São testes elaborados pela nossa equipe, não têm mais a ver diretamente com os testes do LURIA. São testes para avaliar percepção, memória, atenção, inteligência envolvendo a Neuropsicologia Cognitiva. A validação deste instrumento deve terminar este ano e pretendemos colocar os testes no mercado para serem estudados e avaliados.

Optei pelo magistério porque era uma necessidade premente. Eu tinha convite para permanecer na Europa, porém, voltei para o Brasil porque acreditava que teria uma maior contribuição a dar. Não trabalhei com clínica porque o magistério me envolvia totalmente, embora se tivesse feito clínica teria gostado imensamente.

Pergunta: Quais as qualidades que você considera importantes para o exercício da profissão de psicólogo?

Resposta: Dentro da linha existencial que é a minha escolha, a grande qualidade que o psicólogo precisa ter é ser gente. Dos quase sete, oito, nove mil psicólogos que passaram pelas minhas mãos, o que eu tenho observado: eu os vi como alunos, os vi iniciando a carreira e agora sou convidado para comemorar 20, 30 anos de formatura. Aqueles que realmente foram mais gente, foram os que se deram bem na profissão.

O que significa ser gente? É você investir na própria personalidade. Isso não significa ser mais do que os outros. Isso é bobagem, qualquer comparação é boba. É olhar para dentro de si próprio, trazer à tona todas as suas qualidades e explorá-las ao máximo em benefício do outro, sabendo que o psicólogo é alguém que presta serviços. Na classificação sociológica, o psicólogo está na classificação terciária, que é serviço. Então o lema do Psicólogo é: "eu devo servir". Mas com que eu vou servir? Com as minhas qualidades que desenvolvi ao longo do curso, as quais me transformaram numa pessoa mais completa. Isso não significa ser mais ou menos inteligente, mais afetuoso ou menos afetuoso. Tem gente que vai precisar de um psicólogo mais frio, racional, outros precisam de colo de uma mãezona. Graças a Deus que existem pessoas de todos os naipes, cada um deve desenvolver o que tem dentro de si. Ser gente é você desenvolver todas as suas qualidades, todas as suas habilidades, levando em conta que não é para si mesmo, então não é narcisismo. Narcisismo é o maior perigo que espreita o psicólogo, ele acha que, pelo que estuda, pelo que viu, pelo que analisa nos outros, pelo que pode ajudar os outros, ele tem a tentação de pensar "eu sou um semi-Deus". Isso é o maior absurdo na vida do psicólogo. Quanto mais ele tem, quanto mais ele sabe, quanto mais ele tem capacidade, mais tem o dever de servir. Então ser gente é ser para os outros e não ser para si mesmo.

Pergunta: Que sugestão ou sugestões você daria para um iniciante?

Resposta: Primeiro que realmente a psicologia vale a pena. Acho que este deveria ser um curso obrigatório para toda a população, todos deveriam fazê-lo porque, sem dúvida nenhuma, ajuda muito. O curso ajuda você a se tornar gente, porque o obriga a refletir sobre si mesmo. O estudo das mazelas, os problemas e desvios do comportamento dos outros também fazem você ver até onde está torto e até onde precisa melhorar.

Investir muito na sua própria formação intelectual. Ler é muito pouco; tem que ler, refletir, discutir. O ideal seria que os alunos de Psicologia fizessem grupos de estudos, independente da faculdade, do seu próprio interesse para poder discutir o que estão lendo. É muito pobre ler apenas para fazer prova.

Formação pessoal, o ajuste de personalidade, o autoconhecimento, conhecimento dos próprios limites, isso vai evitar que você seja narcisista e vai evitar que você pense que é superior aos outros. Eu posso dizer que hoje é melhor fazer psicologia do que quando eu comecei, porque como não havia psicólogos, a tentação era maior, o sujeito se achava o "dono da cocada preta". Hoje existem tantos profissionais, gente que fez tanta besteira que saiu nos jornais, então você começa a vida com muito mais humildade. Hoje o campo está tomado, então ou você é bom e vai ter trabalho, ou você não é bom e não terá trabalho.

Então volto a dizer, primeiro a formação intelectual. Segundo, a formação pessoal, sobretudo o ajuste afetivo emocional e, terceiro, uma inserção intelectual e prática muito forte na realidade brasileira. É inadmissível passar cinco anos estudando grandes autores americanos, europeus que fazem uma análise do sujeito humano, universal e esquecer quem é o homem brasileiro que precisa 
do meu serviço. Antes de mais nada, eu sou psicólogo brasileiro para trabalhar aqui no Brasil e ajudar esse nosso povo. O Psicólogo pode ajudar muita gente. Eu diria que a formação intelectual e afetiva do psicólogo é para ajudar o nosso pobre brasileiro que precisa tanto. se atualizado?

Pergunta: Como você consegue manter-

Resposta: O Psicólogo vai estudar até morrer. Eu acho que sou um privilegiado, porque estudei fora do Brasil e tenho acesso a revistas européias, americanas. Todo ano tenho uma viagem para fora do Brasil onde compro livros recémeditados, que normalmente demoram 4, 5 anos para serem traduzidos.

Muitas vezes tenho trazido para debate alguns temas sobre os quais tenho mais clareza porque sei que isso já foi discutido, debatido, e chegaram a alguma conclusão. Mas aqui ninguém ainda fala porque ainda não tiveram acesso. Atualização é leitura, leitura, leitura. Quando você lê? O dia todo, não pára de ler.

Pergunta: Você se considera um profissional realizado?

Resposta: Eu sou profundamente realizado e posso dizer que em 38 anos de magistério tive uns vinte mil alunos de graduação nas mais diversas áreas. Eu posso dizer que tenho vinte mil amigos. E fico muito feliz de encontrar ex-alunos em congressos e muitos vêm me dizer "o senhor me marcou". Eu sempre tive esta preocupação. Ultimamente, como estou mais livre do magistério, tenho participado muito de congressos, palestras, cursos e me realizo tanto quanto na sala de aula. Hoje eu não trabalho mais, eu me divirto. Eu encaro o magistério como algo muito prazeroso. Poder interagir com o aluno é muito gostoso. Os meus alunos são como meus filhos, não só isso: são meus amigos e eu prezo muito o bem deles. Então o magistério só me trouxe felicidades em todos os sentidos. Eu seria uma pessoa maldosa se dissesse que o magistério me trouxe alguma tristeza.

Pergunta: Qual a mensagem que você deixa para a nossa turma?

Resposta: Vale a pena ser psicólogo, mas vale a pena ser psicólogo muito consciente da sua formação, da sua informação e do seu poder de ajudar muita gente. Uma outra mensagem que eu posso deixar pra vocês como ex-coordenador de cursos de Psicologia, posso dizer que as turmas que foram mais unidas, foram aquelas que tiveram o melhor resultado. Turma unida não significa que todo mundo é vaquinha de presépio, são turmas que muitas vezes discutem, brigam por certas coisas, mas são turmas onde todos olham para a mesma direção, todos procuram o bem um do outro, não só o seu e da sua panelinha. O que mata as turmas são as panelinhas. Ser do contra, não porque se tem uma opinião diferente, mas somente porque foi alguém de outra panela que falou. Eu posso discutir, você tem formação diferente da minha, mas todos devemos arregaçar as mangas e caminhar na mesma direção.

Psicol. Argum., Curitiba, v. 25, n. 50, p. 233-235, jul./set. 2007 